\title{
Preface \\ Controversies in Breast Cancer 2008
}

\author{
William R Miller
}

University of Edinburgh, Paderewski Building, Western General Hospital, Edinburgh, EH4 2XU, UK

Corresponding author: William R Miller, w.r.miller@ed.ac.uk

Published: 18 December 2008

This article is online at http://breast-cancer-research.com/content/10/S4/S1

(c) 2008 BioMed Central Ltd

The Controversies in Breast Cancer 2008 meeting was held at the Royal College of Physicians (Edinburgh, UK) on 1 to 2 September. It was the third such event and had the same objective and format as the previous meetings. The objective was to identify a discrete number of topical areas in breast cancer that were either controversial in terms of being in dispute or that merited debate in order to clarify issues relating to obstacles to progress. To this end, an international faculty of renowned experts was brought together to present perspectives and debate them with an invited audience that reflected a spectrum of disciplines and experience.

The basic brief of the faculty members was to identify the key debating points in their allotted topic while being prepared to 'fly some kites' and be provocative. There was no need to present methodology (unless it was an underlying cause of uncertainty and conflict) or to incorporate unpublished results (although they could be included, and novel interpretation of existing data was most certainly encouraged). In certain instances, individual speakers were asked to put one side of a debate in order to allow another to present an opposing view. All of these elements may be reflected in the proceedings presented here; readers are asked to bear this in mind when considering the texts.

Subject areas were chosen by the chairs. This year they included the following: 'What can surgeons do for us (and we for them)?'; 'Identification of personal risk to breast cancer'; 'Endocrine therapy: where have we come from, where are we at and where are we going?'; and 'Optimizing the implementation of future treatments - time to abandon traditional methods'. There was also a debate on 'Extended follow up of breast cancer patients in the clinic wastes time for both patients and doctors'.

It was poignant that the first session should have a surgical basis. Tim Cooke was St Mungo Professor of Surgery at the University of Glasgow. He was a strong supporter of the Controversies meetings and would have been ever present but for his untimely and tragic death in a road accident some
Breast Cancer Research 2008, 10(Suppl 4):S1 (doi:10.1186/bcr2161)

months earlier. The session and associated proceedings are dedicated to his memory.

Because the intention of the meeting was to provoke debate, a large amount of discussion followed the presentations. It has not been possible to incorporate this into these proceedings. However, the objective is not simply to provide a paper record of the meeting. Instead, the hope is that the texts are thought-inducing, will generate some novel perspectives and will occasionally challenge established dogma. In this way, we may achieve a better understanding of some important problems relating to breast cancer.

\section{Competing interests}

The author declares that they have no competing interests.

\section{Acknowledgement}

Educational grants from AstraZeneca, Novartis, Pfizer and Roche were used to support both the Controversies in Breast Cancer 2008 meeting and publication of these ensuing short articles. This support is gratefully acknowledged.

This article has been published as part of Breast Cancer Research Volume 10 Supplement 4, 2008: Controversies in Breast Cancer 2008. The full contents of the supplement are available online at http://breast-cancer-research.com/supplements/10/S4. 